\title{
Eating rough: food sources and acquisition practices of homeless young people in Adelaide, South Australia
}

\author{
Sue Booth* $\dagger$ \\ School of Public Health, Faculty of Medicine, Flinders University, Adelaide, South Australia, Australia
}

Submitted 5 July 2004: Accepted 7 July 2005

\begin{abstract}
Objective: The aim of this study was to determine the food sources and acquisition practices used by homeless youth in Adelaide. This work is part of a larger study that aimed to examine the extent and nature of food insecurity among homeless youth. Design: Cross-sectional design involving quantitative and qualitative methods.

Setting: Four health and welfare inner-city agencies serving homeless youth in Adelaide, South Australia.

Subjects: A sample of 150 homeless youth aged between 15 and 24 years recruited from these agencies. Fifteen were selected via snowball sampling for interview.

Results: Use of welfare food sources was high (63\%). Food from welfare agencies was supplemented by unorthodox food acquisition methods such as theft (65\%), begging for money for food (61\%), begging for food items (44\%) and asking for help from friends and relatives (34\%). Reasons given for non-usage of welfare food services included affordability, access, being too busy, shame or embarrassment.

Conclusions: Food insecurity is a salient issue for some homeless youth in Adelaide. Clarifying food acquisition practices of food-insecure homeless youth is essential for rational planning and improvement of food-related services to meet their needs. Such an understanding also underpins the development of broader public policy responses that improve individual and household skills and resources to acquire food and ensure food security. Nutrition professionals, welfare professionals and policymakers need to work sensitively with welfare food agencies and others to improve food access and food security for homeless youth.
\end{abstract}

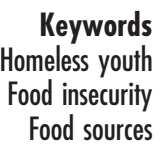

Homelessness is increasing in Australia and of particular concern is the increase in the number of homeless young people aged $12-24$ years $^{1}$, which is estimated to have doubled between 1991 and 1994 to approximately 100000 . Of that number, $20 \%$ are chronically homeless (more than 1 year); about 35\% experience short-term homelessness (less than 2 weeks) and about $45 \%$ are homeless for some months ${ }^{2}$. South Australian data from welfare service providers suggests that homeless youth aged 15-24 years made up 38\% of the total numbers of homeless people seeking assistance ${ }^{3}$.

One consequence of living without stable shelter is the risk of food insecurity, i.e. 'limited or uncertain availability of nutritionally adequate and safe food or limited or uncertain ability to acquire food in socially acceptable ways ${ }^{4}$. Over time, food insecurity may adversely affect the dietary intake and weight status of individuals; for example, it may result in inadequate intake of specific nutrients ${ }^{5,6}$ or under- $^{7,8}$ or overweight ${ }^{8,9}$. Food insecurity among chil-

†Present address: School of Nutritional Sciences, Faculty of Medicine University of Toronto, Fitzgerald Building, 150 College Street, Toronto, Ontario, Canada, M5S 3E2. dren, young people and pregnant women is of particular concern because adequate nutrition is essential for optimal growth and development ${ }^{10}$.

The phenomenon of food insecurity is also occurring in other 'wealthy' countries, as shown by population surveys and studies of vulnerable populations in New Zealand, Canada, the UK and the USA ${ }^{11-14}$. Australia, with its abundant food supply and 'clean and green' food image, has been described as a food-secure country ${ }^{15}$. Yet paradoxically, there are sections of the population who are food-insecure. National and state population health surveys show the prevalence of food insecurity in Australia to be about $7-10 \%$, but these estimates are substantially higher among particular population subgroups, including young people, rental and single-person households ${ }^{16}$. Studies of small samples of groups at risk of food insecurity have been conducted in Australia - for example, on homeless $\mathrm{men}^{6}$, indigenous people ${ }^{17}$, youth $^{18}$ and injecting street drug users ${ }^{19}$ - and show that these groups have a poor-quality food supply and poor diet quality, experience hunger as a result of insufficient food or suffer stress or anxiety about their ongoing ability to acquire food. 
Three Canadian ${ }^{20-22}$ and two American studies ${ }^{23,24}$ provide some information on the experience of food insecurity amongst homeless youth. Three of these studies were primarily investigating other issues; however, data on food insecurity emerged. Key findings included the use of multiple food sources by homeless youth as a means of 'getting by' and a reliance on alternative food sources and procurement strategies to meet ongoing food needs. These included retrieving food from rubbish bins, 'squeegeeing cars', begging and theft.

Four Australian studies provide a glimpse of the extent of food insecurity amongst young people; two were sexual health studies of homeless youth ${ }^{25,26}$, one investigated general aspects of life for homeless youth in Brisbane ${ }^{27}$ and one was an examination of food intake of disadvantaged youth in Sydney ${ }^{18}$. These limited data describe the inability of homeless youth to access a healthy food supply without worry or stress, coping mechanisms, and the procurement of food via alternative strategies such as survival sex. Work by Davies ${ }^{18}$ has limited value because it is not clear whether the study population of disadvantaged youth was homeless or not.

However, no published studies primarily investigating food insecurity amongst homeless youth in Australia exist. This is an important gap because the numbers of homeless youth are increasing and also food insecurity has been identified as key issue for further elucidation and action in Australian national and state public health nutrition strategies $^{28,29}$. Thus, this is the first study to report on an investigation of the experience of food insecurity among homeless youth in Australia.

\section{Methods}

Between March and August 2000, 150 homeless youth were recruited from four agencies that provide services, including two youth shelters, a youth-specific health service and a Christian-based coffee shop in Adelaide. These agencies represented the majority of youth-specific services in Adelaide. Recruitment strategies included word of mouth amongst homeless youth, agency staff referrals as well as from workers in needle \& syringe exchange programmes, posters and postcards. The latter were commissioned by a young artist who had previously been homeless and were placed in youth-specific agencies and handed out to waiting clients and participants.

A cross-sectional study design was employed using both quantitative and qualitative methods. A 41-item selfadministered questionnaire collected information about where participants obtained food, food purchasing behaviour, frequency of eating, self-rated health and demographic characteristics. All participants had their height and weight measured. Semi-structured interviews conducted by a nutritionist with training and experience in qualitative research sought more detailed information from a subsample of 15 youth about food sources and difficulties in acquiring food, attitudes and experiences to do with these aspects of food, and ideas about how their food security could be improved. Interviewees were selected to represent a range of experiences, based on age, gender, length of homelessness and previous episodes of homelessness. Ethics approval was obtained from the Flinders University Social \& Behavioural Research Committee.

To be eligible participants had to be aged between 12 and 24 years, have been homeless for a minimum of four weeks, be English-speaking, literate and lucid. Chamberlain and MacKenzie's definition of homelessness ${ }^{30}$ was used and all participants were experiencing either primary or secondary homelessness. Primary homelessness refers to people without conventional housing, including those living on the streets or in squats. Secondary homelessness includes people who are moving between one form of temporary accommodation and another, including friends and emergency accommodation. Lucidity of participants was measured subjectively by the author. Two participants were clearly drug- or alcohol-affected and unable to complete the questionnaire. Under these circumstances the interaction was terminated and participants paid for their time. The interviewer was available at particular services at designated times and homeless youth would call in to take part. All interviews and measures were conducted in a private room within the agency. Standard questions including their age and current length of homelessness were asked to determine their eligibility. After the study was explained in detail to participants, consent was sought at the time of questionnaire and interview. Verbal consents were tape-recorded and homeless youth were paid \$A10 for their participation. The data presented in this paper come from the questionnaire and the interviews.

Questionnaire data were analysed using SPSS version 10.0 (SPSS Inc., Chicago, IL, USA). Distributions for responses to questionnaire items were checked, and relationships between questionnaire items and sociodemographic characteristics, such as gender, age, length and previous episodes of homelessness, were assessed using Pearson chi-square tests. $P$-values of $\leq 0.05$ were considered statistically significant. For the qualitative interview data, a coding scheme was developed on the basis of key themes emerging from the interviews ${ }^{31}$. Data were sorted according to emergent themes ${ }^{32}$ and the data managed and analysed using NUD*IST version 7.0 software (QSR International, Melbourne, Australia).

\section{Results}

\section{Sample demographics}

Key sociodemographic characteristics of the total sample $(n=150)$ are shown in Table 1 . Eighty per cent $(n=120)$ of participants indicated they had been homeless before and of these $42 \%(n=50)$ were currently aged $15-18$ 
Table 1 Key sociodemographic characteristics of the homeless youth participants $(n=150)$

\begin{tabular}{|c|c|c|}
\hline Characteristic & $n$ & $\%$ \\
\hline \multicolumn{3}{|l|}{ Age } \\
\hline Range (years) & \multirow{2}{*}{\multicolumn{2}{|c|}{$\begin{array}{c}15-24 \\
19.0(\mathrm{SD}=2.6)\end{array}$}} \\
\hline Mean (years) & & \\
\hline $15-18$ years & 67 & 45 \\
\hline $19-24$ years & 83 & 55 \\
\hline \multicolumn{3}{|l|}{ Gender } \\
\hline Male & 81 & 54 \\
\hline Female & 69 & 46 \\
\hline \multicolumn{3}{|c|}{ Previous episodes of homelessness } \\
\hline Yes & 120 & 80 \\
\hline \multicolumn{3}{|c|}{ Current length of homelessness - self-report } \\
\hline Range & \multirow{2}{*}{\multicolumn{2}{|c|}{$\begin{array}{c}4 \text { weeks }-2 \text { years } \\
5.95(S D=3.1)\end{array}$}} \\
\hline Mean (months) & & \\
\hline \multicolumn{3}{|c|}{ Total $^{*}$ length of homelessness - self-report $(n=120)$} \\
\hline Chronic ( $\geq 12$ months) & 82 & 68 \\
\hline Long-term (<12 months) & 38 & 32 \\
\hline \multicolumn{3}{|l|}{ Recruitment site } \\
\hline Youth shelters & 72 & 48 \\
\hline Youth health service & 48 & 32 \\
\hline Christian drop-in & 30 & 20 \\
\hline \multicolumn{3}{|c|}{ Anticipated sleeping site for the coming week $(n=148)$} \\
\hline Don't know & 50 & 34 \\
\hline Crisis accommodation & 56 & 38 \\
\hline Friends & 22 & 15 \\
\hline Rough & 13 & 9 \\
\hline Rental & 4 & 3 \\
\hline Other & 3 & 2 \\
\hline
\end{tabular}

SD - standard deviation.

${ }^{*}$ Being the sum of all previous episodes of homelessness.

years. There was a significant association between being male and having been homeless previously $(P=0.001)$

\section{Qualitative interviewees}

A sub-sample of nine females and six males ranging in age from 15 to 23 years was interviewed. Of the females, five were under 18 years and four were over 18. Males ranged in age from 18 to 21 years. With the exception of two girls aged 15 and 16 years, all had previously been homeless. Interviewees' self-reported length of homelessness ranged from 2 months to 5.5 years.

\section{Major food sources of bomeless youth}

Survey respondents were asked 'Where do you get most of your food from? and more than one response was possible from a list of 10 identified sites. Table 2 shows the range of sources where homeless people reported obtaining most of their food.

Both survey and interview data confirm that homeless young people do not rely on a single food source, rather they use multiple sources. Both questionnaire and interview data on specific food sources are presented below.

\section{Welfare agencies}

Questionnaire data found that 63\% $(n=94)$ of all respondents reported using services which provide free or cheap meals in the city. Open-ended survey responses
Table 2 Reported sources of food for Adelaide homeless youth $(n=149)$

\begin{tabular}{lcc}
\hline Site where most food was obtained $^{*}$ & $n$ & $\%$ \\
\hline Hostel/emergency accommodation & 67 & 45 \\
Supermarket & 60 & 40 \\
Takeaway outlet & 52 & 35 \\
Church/welfare organisation & 52 & 35 \\
Friends \& relatives & 50 & 34 \\
Fred's Van†/soup van & 50 & 34 \\
Deli, café, coffee shop & 43 & 29 \\
Hospital, pub, Hare Krishna & 15 & 10 \\
Otherł & 12 & 8 \\
Don't know & 4 & 3 \\
Rubbish bins & 3 & 2 \\
\end{tabular}

* Multiple responses possible - total $=408,149$ valid cases, one missing case.

†Fred's Van provides food to homeless people in the city four nights a week (Tuesday, Wednesday, Thursday and Sunday). The van is operated by St. Vincent de Paul and volunteers and distributes a range of donated and prepared food including sandwiches, fruit, cakes, soup, bread and barbecued sausages.

$\mp$ Sources of food identified in the 'Other' category included theft $(n=4)$ detoxification centre $(n=1)$, produce markets $(n=1)$ or Teen Challenge, a specific welfare service $(n=2)$. Four did not provide details of the alternative food source.

were categorised and four main reasons were given for the use of food welfare services: they give food of good quality; they were convenient to where homeless youth were 'hanging out'; they were familiar, felt safe and/or there was a likelihood of meeting up with friends; and/or no alternative food sources were available. Open-ended questionnaire responses for not using welfare food services have been categorised and are shown in Table 3 .

Shame or embarrassment was a salient issue for some in obtaining assistance from welfare food agencies and may contribute to food insecurity. Typical responses included: 'Because I'm no hobo' (inferring they did not wish to be associated with an older 'skid row' type clientele); 'I feel a bit embarrassed going to these places, I look for other alternatives first'; and 'I'm no beggar, its too shameful'.

Theft

Stealing food was reported by $65 \%(n=98)$ of questionnaire respondents and of these, $69 \%(n=68)$ did so 'sometimes' and 31\% $(n=30)$ did so 'often'. Those who had been homeless before were more likely to have stolen food than those who had not $(P<0.05)$. Fifty-two per cent reported stealing money to buy food. Those more likely to

Table 3 Reasons given by Adelaide homeless youth for not using welfare food agencies $(n=56)$

\begin{tabular}{lrr}
\hline Category & $n$ & $\%$ \\
\hline Miscellaneous*/Other reasons & 16 & 29 \\
Didn't know the location or existence of service & 15 & 27 \\
Shame/embarrassment & 9 & 16 \\
Prefer to purchase own food & 7 & 13 \\
Prefer to use alternative food sources & 6 & 11 \\
Unpalatable/unhygienic food at welfare food agencies & 3 & 5
\end{tabular}

* Miscellaneous reasons included: affordability, access, a limited desire or need to eat and being too busy to go to a welfare food service. 
have stolen money to buy food were males $(P=0.04)$ and those who had been homeless before $(P=0.02)$. For some, theft of food was seen as a last resort when other efforts to obtain food had failed, as 'Geoff', aged 18 years, explained during interview: '. . if I got rejected from one place [a welfare agency] I wouldn't try that place again...I'd probably go off and steal something [food]'.

\section{Deliberate temporary incarceration}

Four of the fifteen interviewees used overnight alcohol detoxification facilities $(n=2)$ or jail $(n=2)$ as a legitimate food source. Deliberately offending in order to be jailed was seen as a valid strategy by some for obtaining food. 'Leo's' experience was typical: '. . . but the only way to get food is to get pissed and go to detox, or end up in the watch house or something like that...if that's the only way to get food you do it'.

Food quality and portion size in jail were perceived as being much better than the food available on the streets and, as such, desirable and worthy of incarceration, as 'Dimitri' explained: 'Oh, at least you get stews, lasagne, fish and chips all that. People think it's hard in there [jail], it's not. You get like decent meals and that, and it's a free roof over your head... It's just like a laugh 'cos half the time it's [the food] better in jail'.

\section{Begging}

Also referred to as 'biting up' or 'scabbing up' in street vernacular, begging for money or food was commonplace among both genders. In response to the questions 'Have you ever done any "biting up" for food?' and 'Have you ever done any "biting up" for money to buy food?', $44 \%$ (63/144) of all questionnaire respondents had begged for food items per se. There were no significant differences in begging for food according to age, gender, length or frequency of homelessness. Sixty-one per cent (88/148) had begged for money to spend on food. Those who had been homeless before were more likely to have begged money for food $(P=0.02)$.

'Biting up' may also be a highly organised activity with some young homeless people operating systematically in large groups in order to maximise their return. 'Tracey' explained: 'Yeah there was this one bloke we beat up on [past tense of biting up]... one day he realised there was a big mob of us (30-40) on the streets and he gave us $\$ 20$. We got a bucket worth of chips, a big bucket...you know one of those big white buckets that you buy mayonnaise and stuff in catering...'

\section{Friends and relatives}

Thirty-four per cent of all questionnaire respondents used friends or extended relatives as a food source. Six interviewees acknowledged this food source and provided details of this type of assistance which included food deliveries to squats, eating at friends' houses and groceries pilfered from friends' pantries. 'Geoff's' comment illustrates the importance of friends as a food source: 'I've gotten food from friends of mine who have just taken it from their household and said... "Here, my Mum spends like $\$ 500$ a week on food, here, take $\$ 50$ worth"... I rely on my friends for a lot of things and I think if I didn't have them, I'd go hungry a lot of the time'.

Some homeless youth report feeling embarrassed or shamed by the imposition on friends and relatives and for some it was a source of conflict.

\section{Food purchases}

Nearly three-quarters of homeless youth $73 \%(108 / 148)$ purchased food several times per week. Eighty-one per cent of questionnaire respondents $(n=121)$ spent $\$ \mathrm{~A} 50$ or less a week on food - an average of \$A7 per day or less. There was a significant difference in the amount of weekly food expenditure in relation to age, with 19-24-year-olds spending more on food than $15-18$-year-olds $(P=0.01)$. There were no differences in the weekly food expenditure according to gender, length or previous episode of homelessness.

Questionnaire respondents were asked to estimate the total amount of money received per fortnight from all sources. Estimates ranged from \$A69 to \$A650, with a median of $\$ \mathrm{~A} 265$. There was a heavy reliance on government welfare payments with 68\% (97/143) of respondents in receipt of the Youth Allowance payment. The place of food in homeless young people's spending priorities was dedicated in response to the question, 'If you had an extra $\$ 20$ a week, what would you spend it on?' Food was the second highest priority for discretional spending after cigarettes/alcohol.

\section{Rubbish bins}

Questionnaire data found use of rubbish bins as a food source was low, with only 14 individuals reporting bin use. Procurement of food from rubbish bins was perceived as a 'last resort' and associated with feelings of shame and embarrassment. 'Con' aged 19 years, who had been homeless for 5 months, explained during his interview: 'The lowest I've gone in getting food was...I've eaten popcorn out of a bin one time. That's the lowest I've gone and I was pretty ashamed of that too'. Interview data also suggests 'scabbing up' money or begging was a better alternative to scouring through rubbish bins.

\section{The kindness of strangers}

Some homeless young people received assistance from individuals including food donations from produce market vendors, restaurants or the general public. One in five questionnaire respondents $(n=30)$ reported acquiring leftover food from food outlets. Often these were one-off episodes in response to a request for help, but others involved semi-regular contact with a trader. The types of food offered by shops and cafes to homeless young people ranged from fast-food meals to fruits and 
vegetables to restaurant meal leftovers. During her interview, 'Kate', aged 20 years, illustrated this type of food acquisition: 'I was walking up and down Russell Street at 2 o'clock in the morning and I was asking all the restaurants and they said 'no' and then I came across this one restaurant that said yes, we do have some leftovers, why, would you like them. I said I'd love them please, so he gave them to me...I had enough food to eat that night and the next morning...'

\section{Sex for favours}

Sex for favours or 'survival sex' involves offering sex in exchange for a range of items such as money, food, cigarettes or a bed for the night. This was not a specific question asked in either the survey or interview; however, it was raised by some respondents during the course of interview. Of those who mentioned sex for favours none admitted involvement, although all had some knowledge of peers engaging in the practice.

\section{Discussion}

It is evident that homeless young people in this study do not rely on a single food source or procurement method; rather they use one or two primary sources which they supplement with other food acquisition practices. The range and combinations of food sources used by homeless young people in this study are similar to those in other studies of homeless youth in Canada, Scotland and the $\mathrm{USA}^{20,22,24,33}$. However, use of deliberate incarceration as a food source or the experience of shame as a barrier to food access has not been previously reported in the literature.

Nearly two-thirds (63\%) of respondents used welfare food sources. International work confirms that charitable or welfare organisations are the single most common food source for homeless youth, albeit to a lesser degree. Usage levels among homeless youth in two different Canadian studies ranged from $19 \%$ in $1997^{22}$ to $23 \%$ in $1998^{20}$. In the USA, Whitbeck and $\mathrm{Hoyt}^{24}$ reported that $20 \%$ of homeless youth used social service drop-in centres. The highest levels have been reported in a study of the health and wellbeing of homeless people in Glasgow, where $50 \%$ of $16-$ 24-year-olds used welfare food sources ${ }^{33}$. A reliance on other combinations of food sources or feelings of shame or embarrassment may account for lower-level usage.

A heavy reliance on welfare food provision services is perhaps not surprising given that two shelters were major data collection sites for the study. Given the sampling methods and size, the data should be interpreted cautiously. They may not apply to all homeless youth in Australia, especially those living in outer metropolitan or country areas. Nevertheless, our data provide an important insight into the dynamics of food insecurity among young homeless people.

Despite a heavy reliance on welfare food sources, other food sources/acquisition practices were well used. Rates of food theft were high, with two-thirds reporting they had stolen food at some time. Theft of food may occur to supplement a limited intake or in response to poor-quality food. In comparison, a Canadian study of homeless youth reported that $47 \%$ had stolen food since leaving home ${ }^{22}$ and only $23 \%$ of homeless youth in a North American study cited stolen food as a source ${ }^{24}$. Theft of food in this study was significantly associated with having been homeless before, suggesting that theft of food may be an adaptive behaviour in response to homelessness.

Begging was a fairly common activity. Experiences of homeless youth having begged for money for food were more prevalent than begging for food items. A study on the extent and nature of begging in Melbourne suggested that fewer than 10 adults were begging in the central business district on any single day ${ }^{34}$. The American equivalent - 'panhandling' - was a food source for only $13 \%$ of homeless youth ${ }^{24}$. Differences in the levels of begging and other unorthodox food sources reported in this and other studies may be underestimates and related to the perceived stigma and shame associated with the practice.

Being homeless was a clear predictor of food insecurity. Those who had been homeless before were more likely to have stolen food, stolen money to buy food or begged money for food. It may be that a previous experience of homelessness has exposed young people to unorthodox food sources and acquisition methods, and these are used more readily on subsequent occasions of homelessness.

Although the data are limited, food sources such as engaging in sex for favours or deliberate temporary incarceration may be examples of 'hidden' food sources and ones which are associated with a greater degree of stigma for homeless young people. Given the stigma attached to these food sources, the data on these methods may be underestimates. Furthermore, food sources such as rubbish bins, begging, theft and premeditated selfincarceration suggest that some homeless people may operate at the survival level of Maslow's hierarchy of needs ${ }^{35}$. Food procurement at the survival level may involve deviation from normal codes of behaviour ${ }^{36}$, regardless of the stigma, and the food sources and practices described by some homeless youth in this study are consistent with this.

Expenditure on food by homeless youth (\$A50 per week) was less than the average weekly expenditure of single-person households in the lowest quintile for gross income (less than \$A301 per week) ${ }^{37}$. Households in the lowest quintile for gross income, of which 64\% were single-person households, spent an average of \$A67.15 on food and non-alcoholic beverages in 1998-99. Attempting to purchase three meals per day on an average of \$A7 per day or less is almost impossible for homeless youth, especially considering food is often more expensive in the city. The price of a sandwich and a drink in the inner city is usually around \$A8-10. 


\section{Conclusion}

The range and prevalence of food sources and unorthodox food acquisition methods among homeless youth suggest high levels of food insecurity, despite the existence of an Australian welfare state and a network of emergency food provision agencies in Adelaide. As a primary prevention strategy, continued effort in developing public policy is required to reduce homelessness, particularly among young people. This in turn would reduce the need for subsequent nutrition and health interventions.

Aspects of food insecurity such as limited food access may impact on the both weight and nutrient intake of homeless populations. Studies have found evidence of overweight/obesity and suboptimal levels of a range of nutrients including iron, calcium, folate, $\mathrm{B}_{12}$, riboflavin, niacin, and vitamins $\mathrm{E}$ and $\mathrm{C}^{7,11,38}$. This is a salient issue for vulnerable groups such as homeless or disadvantaged adolescents and young people, where sufficient nutrition is critical to normal growth and development. More broadly, food insecurity can have real consequences for health and well-being, in terms of stress and worry, unorthodox food acquisition patterns or missing meals ${ }^{24,39,40}$.

While there is a heavy reliance on welfare food sources, the reliance on other food sources would suggest that welfare sources are not serving the needs of homeless people particularly well. Better planned intersectoral approaches are required given the level of food insecurity experienced. Nutrition professionals, welfare professionals and policy-makers have a role to play in the development of sensitive strategies to improve food access and food security for homeless young people.

\section{Acknowledgements}

The City of Adelaide is gratefully acknowledged for providing the author with a Scholarship in Public Health to undertake this study as part of a PhD. I thank Professor Fran Baum, Drs Alison Smith, Louise Hardy and Karen Webb for their helpful suggestions on this manuscript. I am also indebted to all of the homeless young people who participated in this study.

\section{References}

1 Australian Institute of Health and Welfare (AIHW). SAAP National Data Collection Annual Report 2000-01 Australia. SAAP National Data. Canberra: AIHW, 2001.

2 Chamberlain C, MacKenzie D. Youth Homelessness 2001. Research Using Census Data. Melbourne: RMIT University, 2002.

3 Australian Institute of Health and Welfare (AIHW). SAAP National Data Collection Annual Report 2000-01. South Australia Supplementary Tables. SAAP Data Collection. SAAP NDCA Report Series 6. Canberra: AIHW, 2001.
4 Olsen C, Holben D. Position of the American Dietetic Association: Domestic food and nutrition security. Journal of the American Dietetic Association 2002; 102: 1840-7.

5 Carillo T, Gilbride JA, Chan MM. Soup kitchen meals: an observation and nutrient and analysis. Journal of the American Dietetic Association 1990; 90: 989-91.

6 Darnton-Hill I, Ash S, Mandryk J, Mock P, Ho NT. Food sources of homeless men in Sydney. Australian Journal of Nutrition and Dietetics 1990; 47: 13-9.

7 Darmon N, Coupel J, Deheeger M, Briend A. Dietary inadequacies observed in homeless men visiting an emergency shelter in Paris. Public Health Nutrition 2001; 4: 155-61.

8 Luder E, Boey E. Assessment of the nutritional status of urban homeless adults. Public Health Reports 1989; 104: $451-7$.

9 Luder E, Ceyens-Okada E, Koren-Roth A, Martinez-Weber C. Health and nutrition survey in a group of urban homeless adults. Journal of the American Dietetic Association 1990; 90: $1387-92$.

10 Parnell W. Nutritional consequences of poverty in developed countries. In: Mann J, Truswell AS, eds. Essentials of Human Nutrition. Oxford: Oxford University Press, 2002; 613-21.

11 Evans NS, Dowler EA. Food, health and eating among single homeless and marginalised people in London. Journal of Human Nutrition and Dietetics 1999; 12: 179-99.

12 Russell D, Parnell W, Wilson NC, Faed JM, Herbison GP, Horwath CC, et al. NZ Food: NZ People. Key Results of the National Nutrition Survey. Wellington: New Zealand Ministry of Health, 1999.

13 Sullivan A, Choi E. Hunger and Food Insecurity in the Fifty States: 1998-2000. Waltham, MA: Center on Hunger and Poverty, Brandeis University, August 2002.

14 Tarasuk V, Beaton G. Household food insecurity and hunger among families using food banks. Canadian Journal of Public Health 1999; 90: 109-13.

15 Rychetnik L, Webb K, Story L, Katz T. Food Security Options Paper - A Food Security Planning Framework and a Menu of Options for Policy and Practice Interventions. Sydney: NSW Centre for Public Health Nutrition, 2002.

16 Rutishauser I, Webb K, Abraham B, Allsopp R. Evaluation of Short Dietary Questions from the 1995 National Nutrition Survey. Canberra: Department of Health and Aged Care, 2001.

17 Cunningham J, Sibthorpe B, Anderson I. Occasional Paper: Self Assessed Health Status, Indigenous Australia, 1994. Canberra: Australian Bureau of Statistics, 1997.

18 Davies L. A Survey of the Eating Habits of Youth in Northern Sydney. Sydney: Northern Sydney Health Promotion, October 1999.

19 Reid G, Crofts N, Hocking J. Needs Analysis for Primary Health Care among the Street Drug-using Community in Footscray Melbourne. Melbourne: Centre for Harm Reduction, MacFarlane Burnet Centre for Medical Research, 2000 .

20 Antoniades M, Tarasuk V. A survey of food problems experienced by Toronto street youth. Canadian Journal of Public Health 1998; 89: 371-5.

21 Dachner N, Tarasuk V. Homeless squeegee kids: food insecurity and daily survival. Social Science \& Medicine 2002; 54: 1039-49.

22 Hagen J, McCarthy B. Mean Streets - Youth Crime and Homelessness. Cambridge: Cambridge University Press, 1997.

23 Greenblatt M, Robertson M. Lifestyles, adaptive strategies and sexual behaviours of homeless adolescents. Hospital and Community Psychiatry 1993; 44: 1177-80.

24 Whitbeck L, Hoyt D. Getting by - survival strategies of runaway adolescents. In: Nowhere to Grow - Homeless and 
Runaway Adolescents and their Families. New York: Aldine de Gruyter, 1999; 83-94.

25 Hillier L, Matthews L, Dempsey D. A Low Priority in a Hierarchy of Need: A Profile of the Sexual Health of Young Homeless People in Australia. Melbourne: Faculty of Health Sciences, La Trobe University, 1997.

26 Tschirren R, Hammet K, Saunders P. Sex for Favours: The 'On the Job' Youth Project. Adelaide: HIV/AIDS Worker Training Project, 1996.

27 Dunbaven A. Welcome to Brisneyland - Life for Homeless Young People in Inner Urban Brisbane. Brisbane: Brisbane Inner Urban Youth Interagency, 2001.

28 Department of Human Services. Eat Well SA - Public Health Nutrition Action Plan (Draft). Adelaide: Department of Human Services (SA), 2002.

29 Strategic Intergovernmental Nutrition Alliance. Eat Well Australia: An Agenda for Action for Public Health Nutrition 2000-2010. Melbourne: National Public Health Partnership, 2002.

30 Chamberlain C, Mackenzie D. Understanding contemporary homelessness: issues of definition and meaning. Australian Journal of Social Issues 1992; 27: 274-97.

31 Willms D, Johnson N. Analysis and interpretation. In: Willms D, Johnson N, eds. Essentials in Qualitative Research: A Notebook for the Field. Hamilton, Canada: McMaster University, 1996; 69-82.
32 Richie J, Spencer L. Qualitative data analysis for applied policy research. In: Bryman A, Burgess G, eds. Analysing Qualitative Data. London: Routledge, 1994; 173-94.

33 Kershaw A, Singleton N, Meltzer H. Survey of the Health and Well-being of Homeless People in Glasgow. Glasgow: National Statistics, 1999.

34 Horn M, Cooke M. A Question of Begging - A Study of the Extent and Nature of Begging in the City of Melbourne. Melbourne: Hanover Welfare Services, June 2001.

35 Maslow A. Towards a Psychology of Being. Princeton: NJ: D Van Nostrand, 1962.

36 Eckstein E. Food, People and Nutrition. Westport, CT: AVI Publishing, 1980

37 Australian Bureau of Statistics (ABS). 1998-1999 Housebold Expenditure Survey, Australia: Detailed Expenditure Items. Catalogue No. 6535.0 Canberra: ABS, 2000.

38 Malmauret L, Leblanc J, Cuvelier I, Verger P. Dietary intakes and vitamin status of a sample of homeless people in Paris. European Journal of Clinical Nutrition 2002; 56: 313-20.

39 Hamelin A-M, Habicht J-P, Beaudry M. Food insecurity: consequences for the household and broader social implications. Journal of Nutrition 1999; 129(Suppl.): 525S-8S

40 Olsen C. Nutrition and health outcomes associated with food insecurity and hunger. Journal of Nutrition 1999; 129(Suppl.): 521S-4S. 